\title{
Digital games and ELT: Bridging the authenticity gap
}

[This is the pre-publication version of Henry, A. (2013). Digital games and ELT: Bridging the authenticity gap. In E. Ushioda (Ed.). International perspectives on motivation: Language learning and professional challenges. Pp. 133-155. Houndmills: Palgrave Macmillan]

\section{Introduction}

In this chapter I will suggest that in cultural contexts such as Sweden where English is an integral part of young people's everyday lives and is encountered and used in a range of out-of-school domains, a particular challenge facing teachers is not so much generating motivation to succeed in long-term competency goals, but rather engaging students in day-to-day classroom activities. Based on the idea that self-authenticity can have a motivating force (Gecas 1991; Vannini 2006; Vannini and Burgess 2009) and drawing on James Paul Gee's recent work on affinity spaces (Gee 2005; Hayes and Gee 2010), I will argue that teachers of English need to create learning opportunities where students can experience the types of creative and self-relevant interaction commonplace in digital gaming. This does not mean that teachers should look to leisure-time domains with an eye to the wholesale import of youth culture content into the classroom, but, rather, that greater scope should be given to aesthetic and personal expression in activity design. In arguing that there is a growing authenticity gap between the English students learn in school and the English they use outside, I will begin the chapter by looking at the sorts of things young people in Sweden do in their free time. 


\section{English in and outside of school}

From having been essentially just a school subject only a couple of decades ago, English is now an integral part of the everyday lives of young people in Sweden, particularly those who are frequent Internet users and digital game players (Sundqvist and Sylvén 2012). This shift in students' encounters with English has serious implications for teaching, not least in terms of motivation. In an alarming evaluation of the state of secondary school English teaching in Sweden, the National Schools Inspectorate (2011) identify two entirely different cultures in which English is encountered - one in school and one out of school - with very few crossovers between the two. Echoing the view of Simensen (2010: 482), who contends that the currently 'most pressing question from an educational point of view is the discrepancy between the language pupils are exposed to in the media and society in general, and the language they meet in the educational system', the Schools Inspectorate concludes that building bridges between these two cultures is of the utmost importance.

The discrepancy between in- and out-of-school encounters with English has real effects on classroom motivation and is something teachers are increasingly confronting in their professional practice. In observations of nearly 300 lessons, as well as analyses of extensive interview and questionnaire data, the Swedish Schools Inspectorate (2011) found that, for some students, English lessons have 
little to offer in developing language competence and instead provide a welcome opportunity during the school day to relax and switch off. The nature of this disengagement is neatly summed up by one practising teacher's recent reflection on the motivational challenges she now encounters in her daily work:

As a teacher, I often feel stunned by the miracle of learning; 12-yearold pupils arrive to lesson one in a French course with almost no prior knowledge of the language at all and then, after a few months, they are able to understand texts and to communicate with others to some extent. Sometimes I wonder how it happened. Since most pupils come across very little French outside of school, I conclude that the pupils learn the greatest part of the French they know at school and at home, doing homework.

Teaching English is different since the pupils have studied the language for several years when I meet them, at the age of 13-16, and since they are surrounded by English outside of school, watching TV, listening to music or playing computer games, for instance. The miracle of learning that I experience when teaching English is of a different kind; sometimes I am amazed by the fluency and range of vocabulary some pupils demonstrate when they leave school at the age of 16. The two hours of English provided by school every week could hardly explain the level of some pupils' proficiency; it seems likely that they have also benefitted from contacts with the language outside 
of school. This group of pupils sometimes seems slightly bored at school; it is not always easy to create challenging English lessons on different levels at the same time. (Olsson 2011: 1)

That students learn lots of English outside the classroom is by no means a new phenomenon. Ten years ago, in a national evaluation of Swedish secondary school education (National Agency for Education 2003), more than 50 per cent of students reported that they learned as much if not more English outside of the classroom. At the same time, along with maths and Swedish, English was rated as one of the most important subjects in school. Students reported a pleasant classroom environment and, along with music, physical education, home economics and crafts, English was rated as one of the most enjoyable subjects. While the picture painted by the national evaluation is undoubtedly a positive one, there are perhaps early indications even here that students are beginning to take a rather relaxed approach to learning English in school. Its ranking in terms of interest and enjoyment alongside other less demanding and academically more peripheral subjects may be an indicator, as identified by Olsson (2011) and the Schools Inspectorate (2011), that students' growing confidence in their ability to learn English in their free-time means that, most of the time, it is fine just to coast along in class.

So where might this rather laid-back approach to classroom work stem from? What sorts of things are students doing in their free time that lead them to believe they can learn more English outside school and can afford to sit back and take it easy in class? 
It is quite apparent that in the last 10 years the types of things young people do in English have changed radically. Even though English-language interactive games such as Sim City, Doom and Warcraft have been around since the beginning of the 1990s, it was not until the mid-2000s with the increase of affordable PC ownership, high-speed Internet connections, and advances in graphic design in games such as The Sims (2000), World of Warcaft (2004) and Counterstrike (1999), that gaming lost its 'nerdish' tag and became a mainstream activity for young people of both sexes. As we will see, digital gaming (both role-playing and casual gaming) is today the most common leisure-time activity among young people in Sweden.

\section{Digital gaming}

Quite a lot is known about the leisure-time activities of young people in Sweden. Since 2005 the National Media Council (Mediarådet) has regularly produced data on the population's media use. As the most recent report clearly shows, the biggest change in young people's leisure-time activities over the past five years has been the shift away from watching TV and DVDs, playing console-based offline digital games and hanging out with friends in real time, to online PC-based digital gameplaying and social networking via PCs and mobile phones. While social networking - via for example Facebook and MSN - takes place almost exclusively in Swedish, on- and off-line computer and console-based gaming is done entirely in English. Before looking at the types of digital games young people most 
commonly play, I will first look more closely at some of the trends in young people's media use and free-time activities in recent years (Swedish Media Council 2005, 2006, 2010).

- In 200538 per cent of 9-16 year-olds had a computer in their bedroom. In 2010 this figure had increased to 61 per cent. This can be compared to TVs in bedrooms which, in both 2005 and 2010 was 55 per cent.

- Face-to-face after-school contact with friends has declined dramatically over the period. In 200674 per cent of 9-16 year-olds reported that this was a common activity. In 2008 this had decreased to 64 per cent, and in 2010 to just 58 per cent.

- Across the period after-school Internet use has increased. In 200649 per cent reported Internet use as a common activity. In 2010 the corresponding figure had risen to 59 per cent.

- Watching TV and reading books have both decreased substantially in recent years. While in 200656 per cent of 9-16 year-olds reported watching TV as a common after-school activity, only 47 per cent did so in 2010. For reading books and magazines the number of students reporting it as a common after-school activity fell from 30 per cent in 2006 to just 19 per cent in 2010.

- In 201024 per cent of boys were frequent users (more than 3 hours per day) of computer/TV games. 24 per cent of girls were frequent users of mobile phones. 
- The most common Internet activities reported in 2010 were watching film clips (72 per cent) and playing online games (64 per cent).

- Gender differences in all areas of media use have diminished over the period.

It is evident then that rapid changes have been taking place in young people's recreational habits and patterns of socializing. While the total amount of time spent in English language environments might not have changed quantitatively (children and young people have been watching US-produced TV programs with Swedish subtitles and listening to English language music for years $)^{1}$, the sorts of things that they do in these environments has changed a lot. Today digital gaming not only provides the greatest exposure to English, but also the most intense experiences. Digital gaming is not just a pleasant way to pass the time like watching TV and DVDs. It offers more than this. Players interact intensively both with other players and the game itself. As critical linguist and professor of pedagogy James Paul Gee explains, when playing well-designed digital games 'players feel a real sense of agency, ownership, and control. It's their game' (Gee 2008: 318).

The four most popular digital games played by young people aged 12-16 in Sweden, all of which are English-language mediated, are Counter-Strike (CS), which 18 per cent of young people report playing regularly, World of Warcraft (WoW), 13 per cent, Call of Duty 2 - Modern Warfare (CoD), 10 per cent and The Sims 3, 7 per cent (National Media Council 2010). In addition, 9 per cent of young 
people report playing generic so-called 'casual' online games. Each of the big four games has its own particular characteristics.

Counter-Strike is an online FPS (First Person Shooter) game played either with opponents via the Internet or, commonly in Sweden, in specially designed local area networks at so-called 'LAN meets'. Players are assigned to two teams - one comprised of terrorists and the other of special forces who fight against each other in a range of different environments.

Call of Duty is another online FPS where the action takes place in either contemporary or WWII battlefield settings. Players control individual soldiers who, either alone or together with other players, carry out military operations.

World of Warcraft is a Massively Multiplayer Online Role-Playing Game (MMORG) where thousands of players can be linked to a single server. Players belong to a guild and together combine specialist individual knowledge and skills to fight either against monsters in special dungeons or groups of other players.

The Sims is a strategic relationship game in which players control the daily activities and social lives of one or more virtual characters. Unlike the other games there are no missions to be undertaken or points to be gained. Originally developed for PCs, The Sims games can now be played on game consoles or mobile phones. 
Although a full analysis of these four games is beyond the scope of this chapter, it is important, particularly for non-game-players, to appreciate the intensity of the interaction that takes place when playing. All four games encourage, and often demand, cooperation, communication and user-generated input. Because players need to build up sophisticated repertoires of knowledge and skills, and because in games like WoW single players cannot advance in the game without the help of others, communication and cooperation are essential. In contemporary digital games interaction takes place not just with other players, but with the game itself, something that, using terms such as 'authorship', many researchers (e.g. Corliss 2010; Gee 2008) have emphasised. Analogous to the Web 2.0 concept of 'prosumerism' (online activity that involves both 'use' and 'production', see e.g. Goddard and Geesin 2011; Thorne and Black, 2008), authorship refers to the unique input of individual players and is a process that is highly creative and reflexive. Players inhabit and interact in worlds they themselves help to create. Like many other researchers, Corliss emphasises the creative experience of digital gaming:

Through our interactions, we become part of the game, accumulating a degree of authorship always mediated by the constant evaluation of (reward or penalty for) our actions within the game world; these interactions are intensified by a distinct physicality through which we come to embody our digital play and our game learning. (Corliss 2010: 7) 
In a series of influential works in which he analyses the types of learning that take place when playing digital games, Gee $(2003,2008,2009)$ explains how games develop deep feelings of agency. Amongst other things, good games, he argues, mean that players:

- co-design the game through their unique actions and decisions;

- are encouraged to take risks, to explore and to try out new ideas;

- have the opportunity to customize the game to suit their own playing and learning styles

- become producers and not just consumers;

- learn to view the virtual world through the eyes and values of a distinctive identity that is constructed 'from the ground up' (Gee 2008: 318).

\section{Classroom English}

As we have seen, a new type of student seems to have turned up in the English classroom in recent years. Surprisingly proficient in many aspects of English, particularly vocabulary (Sundqvist and Sylvén 2012), but also in processing written information and sometimes also in oral production and interaction, these students don't seem to feel the need to overexert themselves in class (Swedish School Inspectorate 2011). What sort of classroom environment though do these students 
meet? Has there been much change in teaching approach over the same period? The answer, as we might expect, is probably very little. Even though teachers in Sweden have an extremely wide discretion in terms of the choice of content, working approaches and assessment methods, they are nevertheless heavily reliant on textbooks (Swedish Schools Inspectorate 2011), with three out of four English teachers using commercially produced textbooks in essentially every lesson (National Agency for Education 2006). Indeed, compared to teachers of other subjects, English teachers use textbooks to a greater extent and generally tend to use a single book around which they base their teaching (National Agency for Education 2006). While, like other subjects, individual project-type work has become common in recent years, in the 2011 Curriculum a return to more teacherled classroom instruction is clearly signalled. It is therefore no exaggeration to say that, compared to the radical transformations that have recently been taking place in young people's free time activities, it has been pretty much business as usual in the English classroom. Practices that a decade or so ago captured students' attention - when English outside the classroom was encountered mostly via music, film and youth- as opposed to adult-oriented TV programmes (such as the currently popular Family Guy, Desperate Housewives and 21/2 Men) - may not work as well now. A decade ago many of the most highly proficient students probably owed their abilities to hard work in the classroom. Now this may not necessarily be the case. For students who spend hours in digitally-mediated English-language environments outside of school and, moreover, are aware that this is where they gain much of their skills, the English of today's classrooms may by comparison 
seem less meaningful. Less 'real'. A credibility problem seems to be emerging. There would appear to be an authenticity gap between the two different worlds.

How then as educators should we understand and address the emergent phenomenon of a gap between English in school that is still primarily taught as a foreign language (i.e. where textbooks dominate and the focus is on the acquisition of vocabulary, production, reception and, of course, grammar), and the English that outside of school forms the self-evident medium for some of the most personally meaningful activities in which young people currently engage? What does this mean for us as teachers, and what consequences does this have for the way we design lessons? In the remainder of the chapter I will address these questions, arguing that in many classrooms students will rarely have the opportunity to engage in the types of self-congruent activities and forms of learning that are characteristic of the digitally-mediated environments they inhabit outside of school. I will begin however by briefly looking at authenticity in the sense that it is traditionally understood in language education.

\section{Addressing the authenticity gap}

That language classrooms poorly replicate patterns of interaction in real life has long been recognised. Framed in terms of authenticity, academic debate on the problem of the artificiality of classroom language use has largely centred on language production, tasks, assessment, and, most commonly, the content of 
learning materials. Although very little research has been carried out, Gilmore (2007) points to a widespread belief among researchers and teachers alike that authentic learning materials have a positive effect on students' motivation. Justifications offered include the idea that authentic materials are inherently more interesting because they are 'real' and have a 'real' message to convey, that authentic materials can be selected to meet students' specific needs, and that motivation is enhanced when students realize they can actually cope with 'real' texts. In studies that have been undertaken, results have however been inconclusive, leading Gilmore (2007) to conclude that there is very little empirical evidence in support of the claim that authentic learning materials have a positive effect on motivation.

Even if we were to accept the idea that authentic texts - and for that matter authentic tasks and authentic forms of assessment - have positive effects on motivation, it is questionable, as a single strategy, whether a greater emphasis on authentic materials is likely to make any inroads into students' perceptions of a credibility gap between leisure time and classroom English. As a means of addressing this developing problem, the time may have come to start thinking beyond the motivational effects attributed to the authenticity of artefacts (texts, learning materials and tests), and instead consider how perceptions of authenticity in engaging with the language might impact on motivation. By broadening the focus in this way it may become possible to better understand why it is that students who spend hours engrossed in English mediated activities outside of the 
classroom - and who are convinced that such practices form important sites for their learning - seem happy to disengage from classroom activities.

\section{Authenticity as motivation}

As a result of Dörnyei's $(2005,2009)$ recent work on the motivational function of future self-guides, the driving force behind the effort needed to learn a foreign language is today understood in terms of the learner's identification of her-/himself as a future user/speaker of the target language. Pioneering in the true sense of the word, Dörnyei's research has offered new ways of thinking about language learning behaviours and opened up new vistas of enquiry. In particular, by reconceptualising motivation as a consequence of self-related processes, Dörnyei has made it possible for L2 researchers to draw on a wealth of theoretical and empirical research from mainstream psychology, thus making it possible, as MacIntyre, Mackinnon and Clément (2009: 50) put it, 'to map out new conceptual linkages by taking the self as the starting point'. One area that could be usefully explored using a self-based approach is the issue of authenticity, not in its artefact/textual sense, but in the sense of engaging with the language. Let me explain what I mean.

From an 'artefact' perspective, authenticity can be regarded as an evaluative description of the extent to which we perceive something to be real or genuine. Something authentic is what it purports to be: the real deal. Just as authenticity can 
be used as an evaluation of an object, i.e. an authentic text, an authentic Ming dynasty vase or an authentic Donna Karan shirt, so too can it be used in the evaluation of the self or, more precisely, the evaluation of the self at a particular moment in time and engaged in a particular type of activity. In both situations we are making an appraisal. When we consider the authenticity of an artefact the judgment we make would appear to be fairly clear-cut - it either is or isn't a Donna Karan shirt. This we do on the basis not only of the evidence at hand - i.e. the cut, the material, the stitching and, importantly, the label and the tags - but also in relation to an implied referent, i.e. a similar shirt that would be hanging on a rail in the Donna Karan shop on Madison Avenue. When considering possible courses of action or when evaluating our engagement in ongoing actions we make similar assessments. We base our appraisal on emergent evidence - i.e. what we are doing, why we are doing it and for what purpose - which we then compare with an implied referent. In such situations, the referent we use to judge the authenticity of our actions is the collection of core conceptions that we hold about ourselves and which define who we are. Thus, when we evaluate current courses of action, what we are doing is asking 'is this me?' (Gecas 1991; Vannini 2006). This, as Vannini and Burgess (2009) explain, involves a contextual appraisal of our authenticity:

[T] he indicator of realness or authenticity is the degree of congruence between one's actions and one's core self-conceptions - consisting of fundamental values, beliefs, and identities to which one is committed and in terms of which one defines oneself. When actions are congruent with core self-conceptions, one's self is affirmed and one 
experiences authenticity; when one's actions do not reflect or affirm one's core self, one feels inauthentic. This is not to deny that people do not rationalize self-incongruent behaviors or find ways of accounting for such conduct. Rather, our claim is intended to suggest that when actions are defined to be congruent with one's values one will feel affirmed and thus authentic. (104).

From a psychological perspective then, authenticity is the experience of being true to one's self in doing something that fits with who we feel we are, and coheres with our own particular view of the world. In this sense experiences of authenticity are linked to other emotions such as pleasure, satisfaction, contentedness and selfesteem. And, just as with other affective dimensions of motivation, we will be encouraged to do something if we believe that the activity is authentic and involves things that cohere or are congruent with our sense of self (see also Noels' (2009) recent discussion of authenticity from an SDT perspective).

The polar opposite of authenticity is inauthenticity which, because it involves negative feelings of self-contempt and meaninglessness, people struggle to avoid (Gecas 1991). However, because inauthenticity implies engagement in senseless, meaningless activities, it is a self-state rarely encountered. Much more commonly, as Vannini and Burgess (2009) explain, people experience a sense of what they call frustrated authenticity. This arises when the individual feels unable to act in congruence with her/his self-values and, as a consequence, feels frustrated, agitated, dissatisfied and unfulfilled. Not surprisingly, such feelings have a 
negative impact on the willpower and determination to pursue the activity in question.

To be sure, many language students, among their set of core ideas and selfconcepts, will have conceptions of themselves as someone who, for example, is responsible, goal-oriented and conscientious. And these types of self-conception will of course generate motivated classroom behaviours. But this is not the type of self-congruent behaviour that, according to Vannini and Burgess (2009), generates feelings of authenticity. This is because authenticity encompasses an additional element; an aesthetic dimension. Referring to the work of Fine (1996), who suggests that feelings of being authentic in carrying out working tasks are closely related to the aesthetic evaluation of the things that are produced, their argument is that authenticity is experienced not just in any type self-congruent behaviour but, specifically, by engagement in activities from which aesthetic pleasure is derived.

If we now return to consider the way in which young people in Sweden encounter English outside and inside school, the concept of authenticity, and in particular Vannini and Burgess' identification of the importance of the aesthetic evaluation of the products of creative processes, seems to form a useful lens through which to consider differential engagement in English medium activities.

In the creative activities involved in playing the most popular digital games in Sweden (WoW, CS, CoD and The Sims), pleasure and satisfaction are derived not simply from the sense of achievement, for example, in taking out bad guys and 
destroying evil monsters, but also in the aesthetics of the game in creating/customising appealing avatars and developing sophisticated strategies. It is in this way that players can achieve a sense of congruence between core values (who I am) and current activities (what I am doing). The self is affirmed, the individual feels authentic and is motivated to continue with current and similar activities.

But of course playing on- or off-line digital games is not the only arena in which English functions as a creative medium in young people's lives. In the activities of the English classroom, steered by a curricular focus on communicative competence, students are required to be creative in their use of language when writing essays and book summaries, giving oral presentations, or participating in group discussions. However, these types of creative process differ in the emotional resonance they have for the participants and herein, I suggest, lies one of the causes of the authenticity gap. Quite simply, productive language use in the classroom is unlikely to match the more deeply meaningful and self-relevant experiences that young people gain in online environments. In particular, two important factors are often lacking; the value placed in individual creativity and the desire for satisfaction with outcomes and end results.

Here it is important to point out that the research carried out by Vannini and Burgess (2009) was not with young computer gamers but an entirely different group of participants: middle-aged university academics. Although, at first glance, playing multiplayer online role-playing games such as World of Warcraft and 
Counterstrike and doing scientific research might seem worlds apart, they have much in common. Both involve immersion in highly complex contexts. Both demand sophisticated problem-solving skills. Both require dedication and perseverance over long periods of time. Both presuppose an ability to collaborate with others. Both reward innovation and creativity and, most importantly, both activities are highly aesthetic practices that provide participants with 'peak' experiences of self-world fusion.

Turning to look more closely at Vannini and Burgess' (2009) findings, two specific motivational factors seem to emerge; the value of creativity and the desire to achieve end-product satisfaction. When invited to consider the motivational factors in their work, the researchers interviewed talked for example about 'the excitement of doing something new and creative' and 'the creative process and the beauty in the realized form as its ultimate expression'. They also highlighted the 'satisfying success of solving a difficult problem after months or years of work' and the pleasure gained in 'arriving at results and figuring things out' (Vannini and Burgess 2009: 110-11). Explaining how specific motivational experiences gained in one context can impact on motivation in others, Vannini and Burgess make the following important observation:

To suggest that the aesthetic pleasure associated with creation, innovation, and discovery is a motivator is not the same as arguing that these are needs or forces that drive all individuals, always and in all occasions. Rather, we are simply suggesting that the 
meaningfulness of aesthetically appreciating one's work is significant enough and valuable enough to orient one toward seeking similar experiences. (111) [my emphasis].

This, as I see it, seems to encapsulate not only the essence of the relationship between authenticity and motivated behaviour, but also the sense that there might be a gap between different types of activity. Just as the university teachers did not view all of their work in the same way - research and administrative tasks did not provide anything like the same levels of aesthetic appreciation - so might it be the case that students' experiences of their use of English differ between the domains of digital gaming and school. Thus it is not the case that materials used, nor for that matter that communicative activities in classroom English lack authenticity. Nor is authenticity lacking because interlocutors are imaginary or topics of discussion lacking in salience. Rather, the authenticity gap may result more from an orientation to seek similar experiences as those gained in digital gaming and a search for similar types of self-congruent aesthetic experience.

Vannini and Burgess' idea that people involved in aesthetically creative activities orient toward seeking similar experiences in others is an intriguing one and resonates well with another discontinuity, namely Gee's (Gee 2005: Hayes and Gee 2010) identification of a gap between the sorts of learning process implicated in digital game playing and the learning processes that take place in school. Approaching the authenticity gap from a different angle, I will now take a closer look at Gee's ideas and, in particular, his concept of the affinity space. 


\section{Affinity spaces and authenticity}

In his recent research, Gee (2005) has developed the notion of the affinity space as an alternative to Lave and Wenger's well-known concept of 'communities of practice' (Lave 1996; Lave \& Wenger 1991; Wenger 1998). As opposed to a focus on the membership of a community, Gee instead chooses to focus on the spaces in which people interact. In his critique, Gee's point is that people relate to and form an affiliation with the activity taking place within a particular space and not, in Lave and Wenger's terms, with the other members of a community (Gee 2005).

So what is an affinity space? What does it look like? Although a comprehensive discussion of the characteristics of affinity spaces lies beyond the scope of this chapter (interested readers are referred to Gee 2005), of the eleven features Gee identifies, it is important in the context of the current discussion to highlight the generative use of knowledge and the sharing of resources. Characteristic of an affinity space is the ability for people to generate knowledge for particular purposes and which can be used either by themselves or by others (Hayes and Gee 2010). Knowledge is therefore not an exclusive accomplishment, commodity or preserve. Rather, it is something generated in interaction with others and shared, both directly and indirectly, with other individuals. 
Although in developing the idea of affinity spaces Gee draws on his analyses of real-time strategy computer games such as Age of Mythology (Gee 2005: Hayes and Gee 2010) and the anime card game $\mathrm{Yu}$-Gi-Oh (Gee 2005), his project extends beyond gaming and online environments. In his work Gee is always interested in the juxtaposition of informal and formal learning and the characteristics of the environments in which they take place. In particular his aim is to focus on differences in knowledge-generation processes in schools and contemporary popular culture (Hayes and Gee 2010). Thus in his work the affinity space functions as a counterpoint against which classroom practices can be critically examined.

One of the most important differences between learning practices in school and the types of learning that take place in affinity spaces concerns opportunities for personal expression and creativity. As Gee explains, school environments tend not to encourage students to be innovative, imaginative and creative, nor do they reward the types of personal expression and 'thinking out of the box' commonly valued in affinity spaces:

Young people today are confronted with and enter more and more affinity spaces. They see a different and arguably powerful vision of learning, affiliation, and identity when they do so. Learning becomes both a personal and unique trajectory through a complex space of opportunities (i.e., a person's own unique movement through various affinity spaces over time) and a social journey as one shares aspects of 
that trajectory with others (who may be very different from oneself and inhabit otherwise quite different spaces) for a shorter or longer time before moving on. What these young people see in school may pale by comparison. It may seem to lack the imagination that infuses the non-school aspects of their lives. (Gee 2005: 231)

Thinking back to the previous discussion on authenticity, Gee's point about the differing role of imagination in schools and affinity spaces would seem to resonate rather well with Vannini and Burgess' notion of a frustrated authenticity. In the same way that the highly regulated learning environments of school can limit opportunities for aesthetic creativity, opportunities for students to be imaginative and pursue 'a personal and unique trajectory' are similarly restricted. But there is another and, motivationally speaking, even more important similarity. Rather than being oblivious or indifferent to the differing experiences and differences in learning processes characteristic of most classrooms and most affinity spaces, young people, Gee explains, are fully attuned to such types of discontinuity. In particular he makes the point that, because 'many young people today have lots of experience with affinity spaces [they] thus have the opportunity to compare and contrast their experiences with these to their experiences in classrooms' (Gee 2005: 222).

To my mind it is the sense in which students are likely to cross-reference experiences in leisure time and classroom domains highlighted by both Gee and Vaninni and Burgess that, as teachers, we either fail to consider or conveniently 
overlook. It is also the reason why both self-authenticity and affinity space theory seem to have particular relevance for English teaching. For students who regularly play digital games, English is much more than just a communicative medium. Everything - from studying online manuals to communication with other players takes place in English. English is a non-dissociable part of the experience. Thus when they make comparisons between the intense and meaningful experiences gained in interacting with other players and game architectures, and the communicative activities in the English classroom, it may not be surprising that feelings of frustrated authenticity - in the sense of lacking the scope to use the language in the same meaningful and self-relevant ways that it is used in gaming environments - may arise. Full engagement in an activity that lacks the vitality of things done in English in virtual worlds may thus become difficult to sustain.

\section{Implications?}

Before looking at some of the implications that digital gaming might have on classroom motivation, let me first clarify a couple of points. In developing these ideas, I have focused on a particular type of game; online real-time multiplayer role-playing games. Although, as we have seen, large numbers of young people in Sweden play such games - and some of them play them a lot - this is not a universal leisure time activity. While other forms of English-mediated popular culture certainly involve aesthetic dimensions akin to those envisaged by Vannini and Burgess and have some of the characteristics of Gee's notion of affinity spaces, 
I am not making any explicit claims in respect of these activities; my focus here is on digital gaming.

It is also important to make clear that in drawing parallels with self-authenticity and affinity space theory, I am not suggesting that the phenomena these theories describe or the processes they anticipate are the same. Rather, my argument is that both provide useful lenses through which, as teachers of English, we can try to better understand the experiences that many of our students have outside the classroom and the ways in which these experiences lead them to make comparisons with what they learn in school.

So, if these theories can help us understand what young people might see as an authenticity gap between English in school and English outside, what are the implications for classroom teaching? And are there any pointers as to what we can do to increase classroom motivation? I think that there are. However before outlining some ideas I want to sound a cautionary note. While I have argued that students are likely to make comparisons between the things they do in English in their leisure time and what they do in school, and that, as Hayes and Gee (2010) have argued, current popular culture constitutes a form of competition for schools and education, the direct import of popular culture into the classroom may bring problems of its own.

As we have seen in the earlier discussion on authenticity, there is a fairly widespread belief among language educators that students respond better to 'real' 
texts, and many teachers and textbook writers - quite rightly - take young people's interests as a self-evident starting point in instructional design. There is however a risk attached in saturating classrooms with the forms of popular culture students are accustomed to in their leisure time. First, as for example technology-enhanced learning researcher Mike Sharples has pointed out, generally speaking, students do not want school to intrude too far into their personal lives. Thus attempts by teachers to colonise young people's social worlds by, for example, bringing the technologies of social networking into the classroom, may be met with resistance. Consequently, as Sharples explains, there is a need to be clear about 'where the bounds of school lie and where it is not legitimate for formal education to intrude on childhood' (Sharples 2006: 22).

A similar point is made by the German youth sociologist, Thomas Ziehe (2000). Ziehe's argument is that it is important for young people to maintain identity boundaries between who they are in school, and who they are outside. It is not the place of school, he argues, to encroach on the other life spaces students occupy outside of school. Moreover, Ziehe argues that school has an important role to play in enabling young people to develop differentiated identities which, he believes, are necessary when orientating through the complexity of modern life:

To be a student is just one dimension of a young lifeform. School cannot possibly embrace the whole range of possible admissions to experience and knowledge any more. And school has a valid priority only when it concerns the young person as 'student', which is just part 
of the perspective. I believe that the distinction between school/young people will and should remain. But still school should work to build bridges. (Ziehe 2000: 60) [emphasis in the original].

In addressing binaries such as school/free time and formal/informal learning, educational theorists have viewed the intersections between them as particularly fruitful areas for developing knowledge and skills. Not surprisingly, structuring metaphors such as 'bridge building' abound in the literature. For example, as a means of forging links between the formal/analytical activities of school and the informal/experiential activities of leisure time, theorists talk in terms of drawing on differing 'funds of knowledge' (Moll, Amanti, Neff and Gonzalez 1992) creating 'third spaces' (Bhabha 1994; Gutiérrez 2008) and, in an L2 context, developing 'bridging activities' (Thorne and Reinhardt 2008).

From the range of different theories and approaches based on the idea of making connections between different learning/knowledge domains, I have chosen to consider a number of propositions made by Elizabeth Moje and her colleagues (Moje 2006; Moje and Hinchman 2004). One of the reasons for doing this is that Moje, a literacy researcher, takes specific account of motivation in her handling of third space pedagogies. Another is that, in extrapolating ideas from third space and literacy development theory to the particular settings of English language classrooms, Moje's propositions for what she and Hinchman call 'responsive teaching' (Moje and Hinchman 2004) seem particularly interesting. 
Responsive teaching involves the recognition that students' experiences are a necessary part of the processes of knowledge acquisition. However, rather than a 'now and then' filtering of young people's experiences into the classroom, in responsive teaching cross-referencing is systematic:

This perspective on culturally responsive pedagogy argues that it is not enough to bring cultural experiences into classrooms as a way of helping students to connect more effectively to new ideas or as a way of engaging and motivating students, despite the fact that these are important aspects of culturally responsive pedagogy. Instead, this perspective wants to make a permanent space in the classrooms and schools for knowledges and Discourses that have been traditionally marginalized. (Moje and Hinchman 2004: 326)

In advocating a 'responsive teaching' approach that can build bridges and create spaces in between school knowledge and ways of knowing that are not normally valued in school, Moje and Hinchman argue that teachers often view the young people they work with in rather reductive terms on the basis, for example, of their ethnic and/or socio-economic backgrounds. Responsive teaching, they explain, means moving beyond basic positional categories and instead branching out and attempting to incorporate the different social practices that each young person individually engages in into the teacher's overall understanding of the student. This means being aware of the broad spectrum of knowledges and different ways of knowing that are characteristic of young peoples' home environments, their social 
and ethnic communities and, most importantly, the popular cultural practices they engage in. Thus in responsive teaching, not only is there a recognition of different types of knowledge and different types of practice, but also of different identities. Responsive teaching therefore means merging 'the needs and interests of youth as persons with the needs and interests of youth as learners of new concepts, practices and skills' (Moje and Hinchman 2004: 322). Using responsive teaching as a blueprint and by combining the need for intersubjective relationships identified by Moje and Hinchamn (2004), the motivational importance of self-congruent aesthetic creativity explained by Vannini and Burgess (2009) and the learning potential of affinity spaces described by Gee (2005, 2008; Hayes and Gee 2010), I will now make some suggestions for the development of a pedagogy that, in drawing on students' out-of-school experiences, can enhance classroom motivation.

The first step: A better understanding of young people's cultural experiences One of the problems facing teachers is developing a better understanding of youth cultural practices. While we usually have a good idea about the types of things our students do in their free time - digital gaming, playing team-sports, interacting with friends on social networking sites - often we know very little about what this involves. Unless we ourselves or people in our immediate social environment have similar free time interests, we are left to media reports, second-hand information and our own speculation as to what our students actually get up to. As language teachers it is important that we inform ourselves about the things that our students are doing in their free time that involve the use of English. If, as an initial step, we 
are able to gain greater insights into the activities and language use associated, for example, with playing MMORGs, we will be better attuned to opportunities to bridge between school and free time English.

There is however another reason why the lack of a nuanced and in-depth knowledge about the types of things our students do that can be problematic. As Moje and Hinchman (2004) explain, lack of insider knowledge can mean that we devalue youth cultural experiences, particularly those different from our own. In the case of English there is a particular risk that the type of communicative competence we aim at in teaching can function in a way that puts the informal and highly adapted forms of language used for example in digital gaming, on an unequal footing. However, by explicitly recognising the value of non-standard language forms and adopting an inclusive approach to different types of language use, we avoid the risk of appearing to stand exclusively for one particular form of English - school or 'proper' English - which, moreover, is a form pupils rarely encounter outside the classroom. Indeed, if as teachers we expect students to be able to navigate between different types of English that are appropriate in different domains, shouldn't we be able to do so too?

\section{Linking youth culture experiences to target concepts}

While there is of course a limit to the knowledge we can reasonably be expected to possess about our individual students' free time activities, an understanding of common, yet for many of us culturally distant practices, is essential in making specific links between target concepts and English-medium activities outside 
school. As Moje and Hinchman (2004) explain, pulling in as many cultural experiences into the classroom as possible may not be particularly effective (cf. Sharples 2006; Ziehe 2000 above). Even though students might become temporarily very engaged in a particular activity, it is often difficult for them to make connections between out-of-school experiences and the learning objects that are in focus. For deep content learning to take place, the experiences drawn upon need to be relevant to the target concepts (Moje and Hinchman 2004: 342).

So what might this idea mean for the classroom teaching of English? I will try and give some examples. In introducing new vocabulary, the rich virtual worlds of digital games could be used to provide contexts in which new words can be situated and described in terms of references to characters, landscapes, activities, processes and so on. Similarly, in written production, different types of composition, for example argumentative, descriptive, contrastive and narrative texts, can be effectively scrutinised and practised using examples from the complex worlds of digital gaming. Important concepts in written communication, such as different forms of text coherence could for example be exemplified by looking at good and bad examples found in online strategy manuals.

Placing a greater focus on creativity and personal expression As we have seen, digital gaming rewards resourcefulness, intuition and imagination. When playing good digital games there is always a demanding yet ultimately achievable challenge. And, in more sophisticated games such as World of Warcraft and The Sims, great value is placed on authorship and aesthetic 
creation. The sense of being engaged in a self-congruent activity - playing 'my game', doing something that 'is me' - creates the sort of motivated behaviour rarely encountered in schools (Gee 2005). While it would be naïve to imagine that classroom teaching, no matter how innovative, meaningful or 'authentic' it might be, could replicate such levels of engagement over sustained periods, a greater focus on creative activities involving personal expression, such as creative writing and role-playing may be important. This is a point Ushioda (2011: 206) also emphasises, arguing that the more teachers are able to create opportunities for students 'to engage and express their own preferred meanings, interests and voices', the more likely effort will be invested in learning.

Similarly, innovation and creative thinking need to be properly recognised and more fully rewarded. As Gee (2003) explains, risk-taking and experimentation are fundamental in digital gaming. Thus it may be important that, in designing classroom activities, we explicitly encourage students to test boundaries and to use the language in creative ways. Greater scope for creativity in individually-chosen or individually-moulded activities such as personalised blog and wiki compositions may also enhance feelings of self-congruence and authenticity.

Developing networks with affinity space features

In his critique of contemporary classroom practice Gee (2005) makes the point that, compared to affinity spaces, classrooms reward individual rather than collective achievement, favour individual rather than distributed knowledge, and rarely provide students with opportunities for networking with each other. Given 
that students' primary use of English is in network environments, this is an area that teachers can and should develop as an important part of their methodology. Setting up student discussion/working groups on the Internet or the school's intranet with the teacher as a participant could be a particularly fruitful initiative. This type of initiative would resonate well with the so-called 'Dogme' approach to communication in which authentic learner-driven conversational interaction between teachers and students is regarded as crucial in developing language skills (Ushioda 2011). In such environments groups of students could work with either teacher- or self-generated problem-solving tasks or cases. Having many affinity space characteristics - such as collaborative working - which students recognise from free-time online activities, students' voices and identities can emerge in student-student and student-teacher interactions in ways that can feel authentic, meaningful and self-congruent.

\section{Conclusion}

In this chapter I have argued that in countries like Sweden classroom motivation may be negatively affected by students' perceptions that, compared to personally more meaningful leisure time activities such as digital gaming, working with English in school can create feelings of frustrated authenticity. Because students are likely to compare in- and out-of-school learning experiences, teachers of English would profit from a better understanding of young people's leisure time activities. This would enable links to be made between target concepts and 
culturally situated experiences. Further, because as individuals we orient towards activities that provide us with feelings of self-congruence and authenticity, I have suggested that when designing instruction, teachers need to provide students with greater opportunities for creativity and meaningful self-expression.

\title{
Engagement priorities
}

\begin{abstract}
Although the in-school-English / out-of-school-English dissonance highlighted in this chapter may not be a universal phenomenon (although see also Taylor, Chapter 7, and Ushioda, Chapter 12, this volume), the issues raised concerning the extent to which classroom educators should draw on students' experiences of language use outside the classroom are nevertheless likely to be relevant for teachers of most age-groups in most contexts. For teachers of English, the ability to critically engage with students' free-time English language activities and to know how and when to incorporate aspects of out-of-class English in everyday instruction are skills that are likely to become of increasing importance. The following are just some of the many issues teachers need to address:
\end{abstract}

1. To what extent, if at all, might there be a gap between in- and out-ofschool English in the part of the world where you live and work? How do you see future trends? How do you see the future development of inschool/out-of-school discrepancies in exposure to and use of English? 
2. Might there be other ways of addressing the gap between school and free time English than those suggested here?

3. Is it always necessary to try to bridge between the different domains of English use/exposure when teaching? What about the case of students who are academically motivated? What about students who have little contact with English in their free time?

4. In what sense might the gap suggested here be a gendered phenomenon? Might for example 'frustrated authenticity' be more of a problem for boys?

5. As discussed in the chapter, commentators such as Ziehe (2000) argue that there should be clear dividing lines between school and free time, and that it is not the place of education to colonise leisure time domains (see also Stockwell, Chapter 9, this volume). Do you agree? By extension, is there not a case for arguing that there should there be a clear distinction between the English that is learnt in school and that acquired outside?

Notes

1. In 2010 the most popular TV programme for children and young people aged 9-16 was The Simpsons. Family Guy and 21/2 Men were popular among boys, while Desperate Housewives was the most popular programme for girls aged 12-16. Hanna Montana was the most popular 
programme for girls aged 9-12. All of these programmes, with the exception of Hanna Montana, which is dubbed, are English language with Swedish subtitles.

\section{Annotated further readings}

Gee, J. P. \& Hayes, E. (2010). Women as gamers: The Sims and 21 st century learning. New York: Palgrave/Macmillan.

In this recent publication James Paul Gee and Elizabeth Hayes continue their work on the ways in which digital games stimulate deep learning, here based on a series of case studies of women who play The Sims.

Readers interested in Gee's work on learning are recommended to visit his website - jamespaulgee.com - where many of his extremely accessible and thoughtprovoking publications are freely available to download. In addition to the publications listed in the references section below, his article Getting over the slump: Innovation strategies to promote children's learning, although aimed at L1 teachers, also makes very worthwhile reading for teachers of English as a second language.

\section{References}


Bhabha, H. K. (1994). The Location of Culture. London: Routledge.

Corliss, J. (2010). The social science of digital games. Games and Culture, 6(3): 316.

Dörnyei, Z. (2005). The Psychology of the Language Learner. Mahwah, NJ: Lawrence Erlbaum.

Dörnyei, Z. (2009). The Psychology of Second Language Acquisition. Oxford: Oxford University Press.

Fine, G. (1996). Kitchens: The Cultures of Restaurant Work. Berkley: University of California Press.

Gecas, V. (1991). The self-concept as a basis for a theory of motivation. In J. Howard and P. Callero (eds), The Self-Society Dynamic: Cognition, Emotion and Action. Cambridge: Cambridge University Press. Pages 171-88.

Gee, J. P. (2003). What Digital Games Have to Teach us about Learning and Literacy. New York: Palgrave/Macmillan.

Gee, J. P. (2005). Affinity spaces: From ‘Age of Mythology’ to today's schools. In D. Barton and K. Tusting (eds), Beyond Communities of Practice: Language, Power and Social Context. New York: Cambridge University Press. Pages 21432.

Gee, J. P. (2008). Game-like learning: An example of situated learning and implications for opportunity to learn. In P. A. Moss, D. C. Pullin, J. P. Gee, E. H. Haertel, and L. J. Young (eds), Assessment, Equity, and Opportunity to Learn. New York: Cambridge University Press. Pages 200-21 
Gee, J. P. (2009). Literacy, Digital Games, and Popular Culture. In D. Olson and N. Torrance (eds), The Cambridge Handbook of Literacy. New York: Cambridge University Press. Pages 313-25.

Gilmore, A. (2007). Authentic materials and authenticity in foreign language learning. Language Teaching, 40: 97-118.

Goddard, A. and Geesin, B. (2011). Language and Technology. Milton Park: Routledge.

Gutiérrez, K. (2008). Developing a sociocultural literacy in the third space. Reading Research Quarterly, 43(2): 148-64.

Hayes, E. R. and Gee, J. P. (2010). Popular culture as a public pedagogy: Design, resources and affinity spaces. In A. Sandlin, B. Schultz, and J. Burdick (eds), Handbook of Public Pedagogy. New York: Routledge. Pages 185-93.

MacIntyre, P. D., Mackinnon, S.P. and Clément, R. (2009). The baby, the bathwater, and the future of language learning motivation research. In $\mathrm{Z}$. Dörnyei and E. Ushioda (eds), Motivation, Language Identity and the L2 Self. Bristol: Multilingual Matters. Pages 43-65.

Moje, E. (2006). Motivating texts, motivating contexts, motivating adolescents: An examination of the role of motivation in adolescent literacy practices and development. Perspectives 32(3): 10-14.

Moje, E. and Hinchman, K. (2004). Culturally responsive practices for youth literacy learning. In T.L. Jetton and J.A. Dole (eds), Adolescent Literacy Research and Practice. New York: Guilford. Pages 321-50. 
Moll, L. C., Amanti, C, Neff, D. and Gonzalez, N. (1992). Funds of knowledge for teaching: Using a qualitative approach to connect homes and classrooms. Theory into Practice, 31(2): 132-41.

Morrow, K. (1977). Authentic texts and ESP. In S. Holden (ed.), English for Specific Purposes. London: Modern English Publications. Pages 13-17.

National Agency for Education. (2004). Nationell Utvärdering av Grundskolan 2003 (National evaluation of compulsory school in 2003). Stockholm: Skolverket.

National Agency for Education. (2006). Läromedlens Roll i Undervisning (The role of learning materials in teaching). Stockholm: Skolverket.

Noels, K. (2009). The internalisation of language learning into the self and social identity. In Z. Dörnyei and E. Ushioda (eds), Motivation, Language Identity and the L2 Self. Bristol: Multilingual Matters. Pages 295-313.

Olsson, E. (2011). 'Everything I read on the Internet is in English': On the impact of extramural English on Swedish 16-year-old pupils' writing proficiency. Licenciate thesis, Faculty of Humanities, University of Gothenburg.

Sharples, M. (2006). How can we address the conflicts between personal informal learning and traditional classroom education? In M. Sharples (ed.), Big Issues in Mobile Learning. Nottingham: Nottingham University. Pages 21-4.

Simensen, A. M. (2010). English in Scandinavia: A success story. In D. Wyse, R. Andrews and J. Hoffman (eds.), The Routledge International Handbook of English, Language and Literacy Teaching. Milton Park, Oxon: Routledge. Pages 472-83. 
Sundqvist, P and Sylvén, L. S. (2012). World of VocCraft: Computer Games and Swedish learners' L2 vocabulary. In H. Reinders (ed.). Digital Games in Language Learning and Teaching. Basingstoke: Palgrave Macmillan. Pages TBA

Swedish Media Council (2005). Ungar och mediar 2005: Fakta om barns och ungas användning och upplevelser av medier (Young people and the media 2005: Facts on children and young people's media use and experiences). Stockholm: Regeringskansliet.

Swedish Media Council (2006). Ungar och mediar 2006: Fakta om barns och ungas användning och upplevelser av medier (Young people and the media 2006: Facts on children and young people's media use and experiences). Stockholm: Regeringskansliet.

Swedish Media Council (2010). Ungar och mediar 2010: Fakta om barns och ungas användning och upplevelser av medier (Young people and the media 2010: Facts on children and young people's media use and experiences). Stockholm: Regeringskansliet.

Swedish Schools Inspectorate. (2011). Engelska i grundskolans årskurser 6-9 Kvalitetsgranskning (A quality assessment of English in secondary school grades 6-9) . Report 2011:7. Stockholm: The Swedish Schools Inspectorate.

Thorne, S. L. and Black, R. (2008). Language and literacy development in computer-mediated contexts and communities. Annual Review of Applied Linguistics, 27, 133-60.

Thorne, S. L. and Reinhardt, J. (2008). 'Bridging activities', new media literacies, and advanced foreign language proficiency. CALICO Journal, 25(3): 558-72. 
Ushioda, E. (2011). Language learning motivation, self and identity: Current theoretical perspectives. Computer Assisted Language Learning, 24(3): 199210.

Vannini, P. (2006). Dead Poets' Society: Teaching, publish-or-perish, and professors' experiences of authenticity. Symbolic Interaction, 4: 1-20.

Vannini, P. and Burgess, S. (2009). Authenticity as motivation and aesthetic experience. In P. Vannini and J. P. Williams (eds), Authenticity in Culture, Self and Society. Farnham: Ashgate Publishing Ltd. Pages 103-20.

Ziehe, T. School and youth: A differential relation. Reflections on some blank areas in the current reform discussions. Young, 8: 54-63. 